\title{
Predictable changes in predation mortality as a consequence of changes in food availability and predation risk
}

\author{
BRADLEY R. ANHOLT ${ }^{1 *}$ and E.E. WERNER ${ }^{2}$ \\ ${ }^{1}$ Department of Zoology, Erindale College, University of Toronto, Mississauga, Ontario L5L 1C6, Canada and \\ ${ }^{2}$ Department of Biology, University of Michigan, Ann Arbor, MI 48109, USA
}

\begin{abstract}
Summary
Theory predicts that animals will have lower activity levels when either the risk of predation is high or the availability of resources in the environment is high. If encounter rates with predators are proportional to activity level, then we might expect predation mortality to be affected by resource availability and predator density independent of the number of effective predators. In a factorial experiment, we tested whether predation mortality of larval wood frogs, Rana sylvatica, caused by a single larval dragonfly, Anax junius, was affected by the presence of additional caged predators and elevated resource levels. Observations were consistent with predictions. The survival rate of the tadpoles increased when additional caged predators were present and when additional resources were provided. There was no significant interaction term between predator density and food concentration. Lower predation rates at higher predator density is a form of interference competition. Reduced activity of prey at higher predator density is a potential general mechanism for this widespread phenomenon. Higher predation rates at low food levels provides an indirect mechanism for density-dependent predation. When resources are depressed by elevated consumer densities, then the higher activity levels associated with low resource levels can lead to a positive association between consumer density and consumer mortality due to predation. These linkages between variation in behaviour and densitydependent processes argue that variation in behaviour may contribute to the dynamics of the populations. Because the capture rate of predators depends on the resources available to prey, the results also argue that models of food-web dynamics will have to incorporate adaptive variation in behaviour to make accurate predictions.
\end{abstract}

Keywords: Anax junius; anti-predator behaviour; behavioural indirect effects; density dependence; growth rate/ mortality rate trade-offs; interaction modification; interference competition; Rana sylvatica

\section{Introduction}

There is growing evidence of a widespread trade-off between the acquisition of resources and predation risk that is mediated by individual behaviour (reviewed in Milinkski, 1986; Sih, 1987a; Lima and Dill, 1990). Increased effort to acquire resources reduces the probability of death by starvation but increases the probability of death by predation (McNamara and Houston, 1987). If this trade-off is general, then it is no longer possible or useful to think of populations as limited either by food or by predators, because food availability affects the probability of death by predation and predator density affects the probability of death by starvation (McNamara and Houston, 1987).

\footnotetext{
${ }^{*}$ Address all correspondence to Bradley R. Anholt, Department of Biology, Univeristy of Victoria, PO Box 3020, Victoria, British Columbia V8W 3N5, Canada.
} 
Strategic models that explicitly incorporate both the availability of food resources and the risk of predation predict that animals should, under a wide range of fitness functions, reduce their foraging effort at high levels of either factor (Abrams, 1984, 1990, 1991a,b, 1993a,b; McNamara and Houston, 1987, 1994; Werner and Anholt, 1993). Reductions in foraging effort (either the proportion of time active, or the speed of foraging while active) are expected to reduce predation mortality because encounter rates with predators will decline (Gerritsen and Strickler, 1977).

The ecological consequences of such adaptive variation in behaviour are potentially large. First, if depletion of resources by animals is density-dependent and animals increase their activity and mortality rates at low food levels as predicted by these strategic models, then this results indirectly in a positive association between prey density and the probability of death by predation. This density-dependent predation is based on the adaptive variation of prey behaviour rather than predator behaviour (Anholt and Werner, 1995; Peacor and Werner, 1997). Second, if animals reduce their foraging activity at higher abundances of predators, then this should result in lower predation rates per-predator (or resource depression sensu Charnov et al., 1976). This densitydependent reduction in predation success is phenomenologically indistinguishable from interference competition among predators (Abrams, 1984; Ruxton, 1995). Third, the effect of changes in foraging behaviour can propagate through the food-web. For example, Werner and Anholt (1996) demonstrated that large, relatively invulnerable bullfrog larvae that do not respond to predators benefit from the presence of predators because small, vulnerable larvae reduce their foraging effort and thereby reduce their competitive effect. A consideration of the pair-wise interaction rates alone that ignores the modification of behaviour, is unlikely to be successful in predicting the behaviour of the entire web (Abrams, 1991a, 1993b).

Behavioural observations of amphibian larvae suggest that they are simultaneously sensitive to the risk of predation and food level (Horat and Semlitsch, 1994; Anholt and Werner, 1995; Anholt et al., 1996; B.R. Anholt and E.E. Werner, personal observation). How large an effect changes in behaviour associated with changes in food availability or predator density have on mortality due to predation is unclear. Anholt and Werner (1995) demonstrated that bullfrog larvae were less active at high food levels as predicted by the above models, and that this reduction in activity was associated with lower predation mortality.

In the experiments reported here, we simultaneously manipulated the density of resources and the density of predators while keeping constant the number of predators actually capable of inflicting mortality. We use a different predator-prey combination to test the generality of the relationship. We also use several food levels to determine whether the response to food level is a step function or a graded response (Werner and Anholt, 1993). Differences in mortality rates in the non-lethal presence of additional predators can be ascribed to differences in behaviour without the direct mortality effects of these additional predators (Van Buskirk, 1989; Wissinger and McGrady, 1993). Simultaneously manipulating food and predators allows us to examine whether the response of the tadpoles is stronger towards food or predators and whether these effects are additive. Changes in the mortality rates of the tadpoles is strong evidence that their behaviour is sensitive to variation in these environmental factors and that this variation in behaviour is likely to have population dynamic consequences that cannot be ignored.

\section{Methods}

We randomly assigned 100 wood frog (Rana sylvatica) tadpoles weighing $45.4 \pm 13.8 \mathrm{mg}(\bar{x} \pm$ S.D.; stage 26-29; Gosner, 1960) to each of 40 covered circular wading pools $\left(0.73 \mathrm{~m}^{2}\right.$; water depth $0.15 \mathrm{~m}$ ) on 19 May 1993. We added finely ground Purina Rabbit Chow ${ }^{\mathrm{TM}}$ at one of five levels $\left(0.27,0.54,1.09,2.19\right.$ and $\left.8.75 \mathrm{~g} \mathrm{pool}^{-1} ; 0.37-11.9 \mathrm{~g} \mathrm{~m}^{-2}\right)$ immediately prior to the addition 
of the tadpoles. These food levels represented between 3 and $96 \%$ body weight of food per tadpole per day of the experiment. Half of the wading pools began the experiment with eight caged dragonfly (Anax junius) larvae in the penultimate $(\mathrm{F}-1)$ or ante-penultimate $(\mathrm{F}-2)$ instar. The remaining wading pools contained a single caged Anax and seven empty cages. After $24 \mathrm{~h}$ of acclimation to the experimental conditions, we released one dragonfly larva from its cage in every pool to begin foraging. Thus, every wading pool had a single effective predator in it, but half of the wading pools had an additional seven caged predators that were prevented from capturing tadpoles. Tadpoles of a great many species have been shown to respond to the presence of caged predators (Lawler, 1989; Skelly and Werner, 1990; Werner, 1991; Horat and Semlitsch, 1994; Anholt and Werner, 1995; Anholt et al., 1996; McCollum and Van Buskirk, 1996), including R. sylvatica (B.R. Anholt and E.E. Werner, unpublished data).

We removed dragonfly larvae from the wading pools $48 \mathrm{~h}$ later and then counted and weighed surviving woodfrog tadpoles. One replicate of the $1.09 \mathrm{~g}$ food, low predator density treatment combination was destroyed by a raccoon. We ascribed all of the mortality in the remaining pools to predation because virtually no mortality occurs under identical resource levels in the laboratory over these short time spans. Had any tadpoles died for reasons other than predation, their remains would have been discovered.

Woodfrog larvae came from clutches collected in natural ponds on the E.S. George Reserve of the University of Michigan, Livingston County, Michigan, USA. We raised tadpoles in outdoor wading pools and fed them ad libitum on a diet of Rabbit Chow prior to being used in the experiments. We collected Anax larvae from the experimental pond site on the E.S. George Reserve.

\section{Analysis}

We analysed the number of animals surviving by maximum-likelihood in GLIM using binomial errors and the logit link function. We tested statistical significance by comparing the deviance of nested models. Change in deviance (analogous to sums of squares) when a variable is removed from the more complex model is a likelihood ratio test that is asymptotically $\chi^{2}$ distributed with degrees of freedom equal to treatment degrees of freedom (Numerical Algorithms Group, 1987; Aitkin et al., 1989; McCullagh and Nelder, 1989; Crawley, 1993). The deviance of the fully saturated model that included blocks, food levels, predator level and the interaction terms between treatments did not differ significantly from that expected with binomial data (deviance $=33.2$; d.f. $=26, P=0.16$ ). We analysed the mass of surviving animals as a standard two-way analysis of variance with spatial blocks.

\section{Results}

\section{Mass gain}

Increased food level generated an increase in the mass of surviving tadpoles from 44 to $54 \mathrm{mg}$ $\left(F_{1,32}=51.0 ; P<10^{-6} ;\right.$ Fig. 1$)$. Therefore, at the lowest food levels, the animals did not grow and perhaps even started to lose mass. This change is unlikely to be due to selective predation because the smallest change in mass occurs where predation is highest (see below). The increase in mass was not linear, but described a saturating curve. At the highest food levels, increasing food level fourfold from 2.19 to $8.7 \mathrm{~g}$ increased final mass by $3 \mathrm{mg}$, less than $0.5 \mathrm{mg}$ per gram of food. At the lowest food levels, increasing food from 0.27 to $2.19 \mathrm{~g}$ increased final mass by $8.4 \mathrm{mg}$, a more than 4 $\mathrm{mg}$ mass gain per gram of food. There was no detectable effect of additional caged predators on the final mass of tadpoles $\left(F_{1,32}=0.7 ; P=0.40\right)$. 


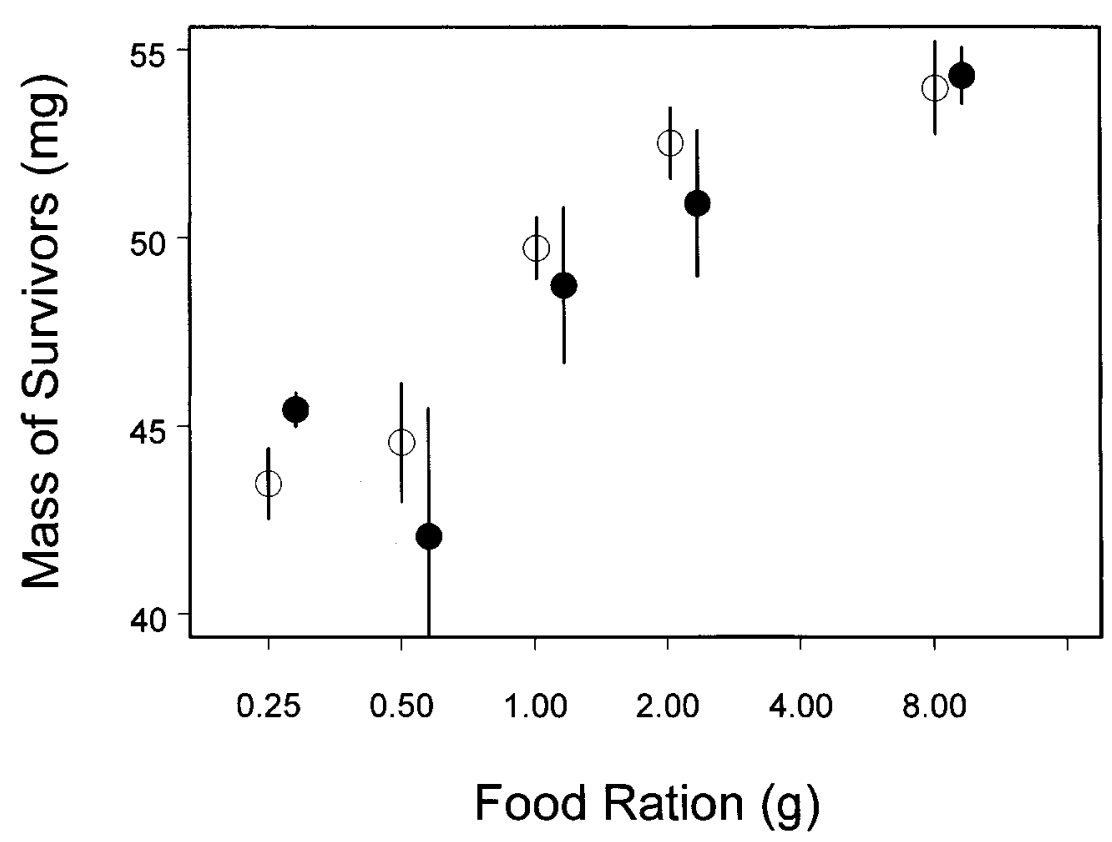

Figure 1. Mean mass and standard error of surviving tadpoles as a function of food ration and the number of predators present: $\bigcirc$, one free Anax and seven empty cages; $\bullet$, one free Anax and seven additional Anax in cages. Symbol pairs are slightly offset from the true food ration to facilitate display.

\section{Predation mortality}

The number of tadpoles killed differed between treatments over the $48 \mathrm{~h}$ of the experiment in the predicted directions. Anax killed fewer tadpoles at higher resource levels. Predation mortality increased from $15.4 \%$ at the highest food level to $26.6 \%$ at the lowest food level; intermediate food levels had intermediate predation mortality $\left(\chi^{2}=33.4\right.$; d.f. $=4 ; P<10^{-6}$; Fig. 2$)$. Mortality also increased from $19.6 \%$ when caged predators were present to $22.7 \%$ when the cages were empty $\left(\chi^{2}=6.9\right.$; d.f. $=1 ; P=0.014$; Fig. 2). The effects of food level and predator density were additive; there was no significant interaction term between food level and predator density $\left(\chi^{2}=2.35\right.$; d.f. $=4 ; P=0.67)$. Likewise, there was no systematic variation due to the blocking term $\left(\chi^{2}=0.3\right.$; d.f. $=3 ; P=0.96)$.

Parameter estimates. The parameter estimates suggest that the tadpoles respond more strongly to food level than predator density. The slope of the relationship between the log of food level and survival predicts that increasing food level eight-fold from 1.0 to $8.0 \mathrm{~g} \mathrm{~m}^{-2}$ (at low predator density) increases survival from 77.6 to $84.7 \%$. Increasing apparent predator density eight-fold (at a food density of $1.0 \mathrm{~g} \mathrm{~m}^{-2}$ ) increases survival from 77.6 to $81.5 \%$.

\section{Discussion}

The mortality inflicted on the tadpoles by a single predator was lower at higher food levels and also when additional caged predators were present. This matches predictions based on strategic models of behaviour that predict reduced activity rates on the part of the tadpoles when resources are more 


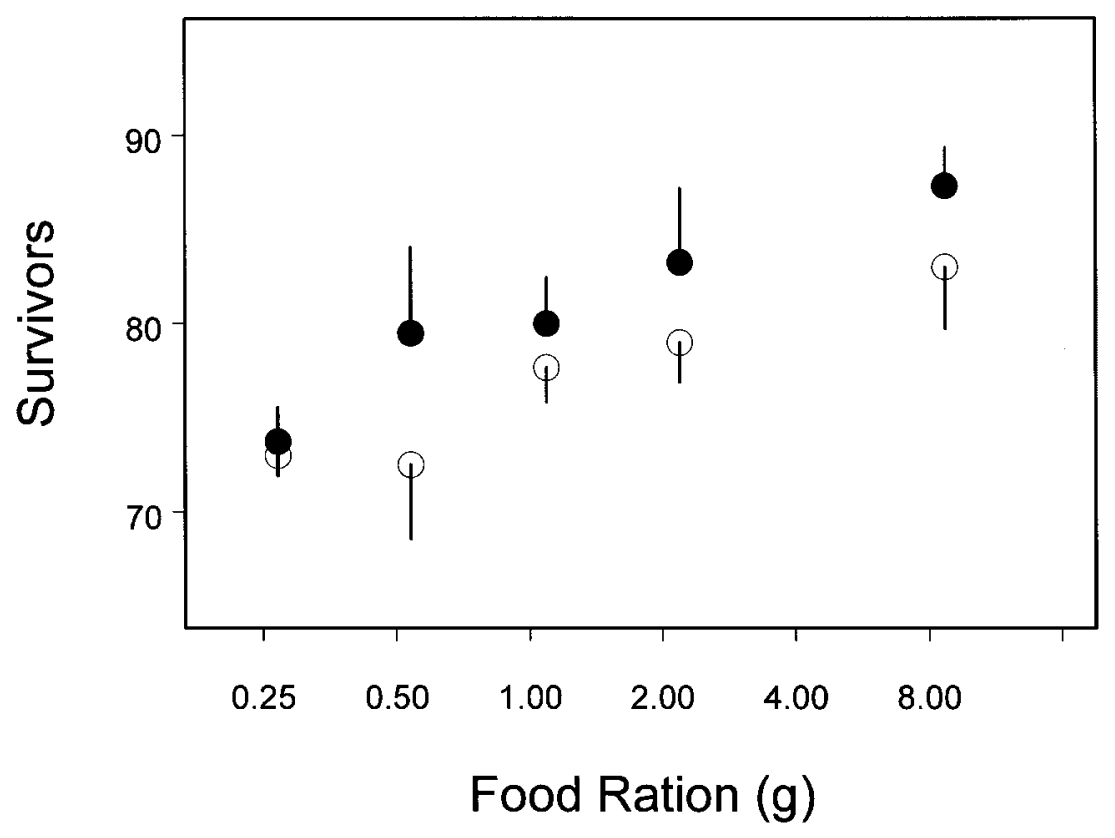

Figure 2. Mean number of survivors and standard error as a function of food ration and the number of predators present (symbols as in Fig. 1). Symbols are not offset.

abundant or when predation risk increases (Abrams, 1984, 1990, 1991a,b, 1993a,b; McNamara and Houston, 1987, 1994; Werner and Anholt, 1993). Rarely, however, has there been evidence that these predicted changes in behaviour affect survival rates.

All of these strategic models predict reduced foraging at increased predator density for which there is abundant evidence (reviewed in Sih, 1987a; Lima and Dill, 1990). There is also growing evidence for reductions in foraging activity by animals at increased food levels (reviewed in Werner and Anholt, 1993), but model predictions are more diverse. Increases in fitness with foraging must be an asymptotic function of foraging effort. In this experiment, tadpoles gained mass at all food levels except the lowest and mass gain increased at a decreasing rate (Fig. 1). Rapid growth and increased mass at metamorphosis are associated with components of fitness such as higher survival, higher fecundity and earlier reproduction in anurans (Berven and Gill, 1983; Smith, 1983, 1987; Woodward, 1983; Berven, 1990). Thus, it appears that the increased benefit of additional foraging by tadpoles is a decelerating function of intake as required by many of the models.

Reduced foraging activity at higher food levels could have generated part of the decelerating relation between mass gain and food availability; however, the presence of predators, which is also expected to affect activity levels, had little effect on mass gain. It seems most likely that the observed relationship is the result of limits to the intake and processing rates of the tadpoles. Abrams $(1984,1993 b)$ has also pointed out that, if the relation between future reproductive success increases more rapidly than the mortality rate with resource acquisition, then this will also favour increased activity in the presence of additional resources. This does not appear to be the case here, but could be in species where body size has strong non-linear effects on fitness. For example, when reproductive success is contingent on winning a territory or oviposition site, small changes in body size can lead to large changes in reproductive success. In a predator-prey context, large differences 
in survival rates can be realized by growing beyond the capabilities of a gape-limited predator. On either side of these rapid changes in fitness, changes in body size might have very limited effects on expected fitness.

It is possible that foraging effort might decline at very low food levels because the intake rate does not repay the costs (Abrams, 1982, 1984). This would result in lower predation mortality at very low food levels. We might have observed this had we used even lower food levels so that the animals began to lose mass.

General treatments of foraging under predation risk (Abrams, 1991b, 1993b; McNamara and Houston, 1994) have pointed out the importance of the persistence of changes in environmental conditions. Short-term increases in food should lead to higher foraging rates, as observed anecdotally by Huey and Pianka (1981). Long-term increases in resources are more likely to lead to lower foraging rates as observed here (additional references in Werner and Anholt, 1993). The manipulations imposed in this experiment represented rapid changes in the environment. Under natural conditions, however, it seems unlikely that natural changes in the availability of resources or density of predators will be transitory, even though the shift from one state to the other is rapid. If predators are present, they will remain so for some time, and if they disappear through emergence, they will remain absent for a long time. Although phytoplankton can bloom quickly in the spring, the persistence of the bloom represents a large portion of the larval life-history of the animals. It seems likely, therefore, that the tadpoles are responding to the experimental treatments as if they will continue to exist in the future. It would be interesting to determine, however, whether the tadpoles can or do respond differently to transitory increases in food availability.

There is widespread evidence that larval anurans adjust their behaviour to the availability of resources and the risk of predation (Skelly and Werner, 1990; Horat and Semlitsch, 1994; Anholt and Werner, 1995; Anholt et al., 1996; Werner and Anholt, 1996). This adjustment in behaviour has consequences for competitive interactions (Werner, 1991, 1992a,b; Werner and Anholt, 1996; Peacor and Werner, 1997) because more active tadpoles tend to accumulate resources more quickly (Skelly, 1992). However, tadpoles with higher activity rates also have a higher risk of predation, both intra-specifically (Skelly, 1994; Anholt and Werner, 1995) and inter-specifically (Lawler, 1989; Azevedo-Ramos et al., 1992). These diverse observations argue strongly that mortality rates due to predation should be related to the availability of resources.

Because the tadpoles must survive every $48 \mathrm{~h}$ period until metamorphosis, the probability of survival to metamorphosis is multiplicative and the cumulative effect can be very large indeed. For example, the observed difference in survival over 2 days of only $4 \%$ represents a nine-fold increase in survivorship when extrapolated over the entire larval period of 90 days. Of course, the vulnerability of tadpoles is not constant. It is probably higher when they are small (before these experiments) and lower when they are large (after these experiments) (e.g. Werner and Anholt, 1996).

We observed a larger effect of an eight-fold increase in food availability than a similar increase in predator density. Several alternative, but not mutually exclusive, explanations present themselves. First, there is a stronger association between food availability and fitness than predator density and fitness. One reason for this might be that predator behaviour is not constant. Anax may change their behaviour because they are also foraging under the risk of predation by other Anax. Odonate larvae in general, and Aeshnidae in particular, are opportunistic cannibals (Van Buskirk, 1989; Wissinger, 1989). Thus, at high predator density, the environment is more dangerous for the predators as well. Wissinger and McGrady (1993) observed that larvae of the libellulid Erythemis simplicicollis reduced foraging activity and predation rate in the presence of other predators. Thus, increasing predator density by a factor of eight may not increase the true or perceived risk of predation for the tadpoles by the same amount, because the per-predator predation rate is declining. In principle, however, variation in behaviour by the predators is not different from that of 
the prey. Therefore, predator behaviour should also be predictable using the same framework and could be incorporated into a more sophisticated understanding of the system.

Second, if increasing predator density increases the risk of predation even at the lowest possible activity level, but does not affect the rate of increase in mortality risk with activity, then the tadpoles should actually increase their foraging activity at higher predator density (Werner and Anholt, 1993). When both the intercept and the slope of the mortality-risk relationship increase with predator density, the exact predictions depend on which parameter changes most. The tadpole response to the increase in predator density is consistent with an increase in the slope of the relationship. That is, they reduce their activity at higher predator density. The only way to separate these alternatives clearly is to estimate the functions directly by measuring activity and estimating the instantaneous probability of mortality.

Third, caged predators may not elicit the same anti-predator responses from tadpoles. Increasing the density of caged predators may not be the same as increasing the density of free-ranging predators. Manipulating Anax by clipping labial palps (Wissinger and McGrady, 1993) may be a better approach for estimating the response of tadpoles to higher predator density. Schaffner (1996) found that damselfly larvae responded to free-ranging Anax manipulated in this way but did not respond to caged Anax.

Finally, the larvae may be incapable of accurately estimating the density of predators and/or resources. The graded response to food levels, however, does show that tadpoles can make distinctions among resource levels.

Adaptive variation in prey behaviour provides a mechanism for density-dependent predation. A large body of evidence shows that, at high densities, tadpoles are capable of depleting their food resources (e.g. Morin, 1983; Wilbur, 1987). A depleted food supply will lead to increased foraging activity by the tadpoles and higher predation rates because of the increased encounter rate with predators. Previous explanations of density-dependent predation have relied on variation in predator behaviour to explain density-dependent predation (Murdoch and Oaten, 1975). Examples include the predator learning to handle prey more effectively or area-restricted search by the predator in areas of high prey density (Curio, 1976). The advantage of an explanation based on the adaptive variation of prey behaviour is that it is more general; it does not require a unique explanation for each predator-prey combination.

Similarly, reduced per-capita foraging success at increased predator density has typically been attributed to interference competition among predators (Beddington, 1975; Weisser et al., 1997), even though direct manipulations of interaction rates may show no effect (e.g. Anholt, 1990). Increases in survival rates at higher predator densities, as shown here, would be interpreted as interference competition when no alternative mechanism is known (Ruxton, 1995). However, reductions in prey availability to the predators because of adaptive variation in prey behaviour, as originally suggested by Charnov et. al. (1976), and theoretically predicted by Abrams (1984), is an equally viable explanation. Both of these mechanisms of density dependence are likely to be stabilizing in their effect because they act without the time delays inherent in many other mechanisms (May, 1981; Ives and Dobson, 1987; Sih, 1987b), although Abrams (1992) shows that, if the effect is large enough, it can be destabilizing.

If adaptive variation in prey behaviour is as widespread as it appears to be (e.g. Lima and Dill, 1990), then attempts to understand population and community dynamics without consideration of that variation may be doomed to failure (Abrams, 1991a, 1992; Werner, 1992b; Wooton, 1993, 1994). Although we do not know whether the observed differences in mortality rate apply over the entire larval ontogeny, small, but real, differences in daily survival rates extrapolated over the length of the larval life history can be very large and cannot be ignored. Clearly, predicting the dynamics of a three trophic level system (predator-prey-resource) on the basis of estimates of the pairwise 
interactions will not work when the capture rate of predators is a function of resource concentration of the prey. However, the apparent generality of trade-off between growth rate and mortality rate offers the tantalizing possibility that relatively simple modifications will allow us to make more realistic and accurate predictions without sacrificing a general framework.

\section{Acknowledgements}

We thank the University of Michigan, Museum of Zoology for access to the E.S. George Reserve. Rekha Trembath provided sterling technical assistance. A. McNeil provided statistical advice. P. Abrams, P. Nonacs and an anonymous reviewer provided valuable comments on an earlier draft of the manuscript and M. Rosenzweig suggested an important reorganization. This research was funded in part by US National Science Foundation grant DEB-9119948 to the authors. The manuscript was completed by B.R.A. during his sojourn at the University of Zurich.

\section{References}

Abrams, P.A. (1982) Functional response of optimal foragers. Am. Nat. 120, 382-390.

Abrams, P.A. (1984) Foraging time optimization and interactions in food webs. Am. Nat. 124, 80-96.

Abrams, P.A. (1990) The effects of adaptive behaviour on the type-2 functional response. Ecology 71, 877-885.

Abrams, P.A. (1991a) Strengths of indirect effects generated by optimal foraging. Oikos 62, 167-176.

Abrams, P.A. (1991b) The relationship between food availability and foraging effort: Effects of life history and time scale. Ecology 72, 1242-1252.

Abrams, P.A. (1992) Why don't predators have positive effects on prey populations? Evol. Ecol. 6, 56-72.

Abrams, P.A. (1993a) Why predation rates should not be proportional to predator density. Ecology 74, 726733.

Abrams, P.A. (1993b) Indirect effects arising from optimal foraging. In Mutualism and Community Organization: Behavioural, Theoretical and Food-web Approaches (H. Kawanabe, J.E. Cohen and K. Iwasaka, eds), pp. 255-279. Oxford University Press, Oxford.

Aitkin, M., Anderson, D., Francis, B. and Hinded, J. (1989) Statistical Modelling in GLIM. Clarendon Press, Oxford.

Anholt, B.R. (1990) An experimental separation of interference and exploitative competition in a larval damselfly. Ecology 71, 1483-1493.

Anholt, B.R. and Werner, E.E. (1995) Interaction between food availability and predation mortality mediated by adaptive behaviour. Ecology 76, 2230-2234.

Anholt, B.R., Skelly, D.K. and Werner, E.E. (1996) Factors modifying antipredator behaviour in larval toads. Herpetologica 52, 301-313.

Azevedo-Ramos, C., Van Sluys, M., Hero, J.-M. and Magnusson, W.E. (1992) Influence of tadpole movement on predation by odonate naiads. J. Herpet. 26, 335-338.

Beddington, J.R. (1975) Mutual interference between parasites and predators and its effect on searching efficiency. J. Anim. Ecol. 44, 331-340.

Berven, K.A. (1990) Factors affecting population fluctuations in larval and adult stages of the wood frog (Rana sylvatica). Ecology 71, 1599-1608.

Berven, K.A. and Gill, D.E. (1983) Interpreting geographic variation in life-history traits. Am. Zool. 23, 8597.

Charnov, E.L., Orians, G.H. and Hyatt, K. (1976) Ecological implications of resource depression. Am. Nat. 110, 247-259.

Crawley, M.J. (1993) GLIM for Ecologists. Blackwell Scientific, Oxford.

Curio, E. (1976) The Ethology of Predation. Springer, Berlin.

Gerritsen, J. and Strickler, J.R. (1977) Encounter probabilities, and community structure in zooplankton: A mathematical model. J. Fish. Res. Board Can. 34, 73-82. 
Gosner, K.L. (1960) A simplified table for staging anuran embryos and larvae with notes on identification. Herpetologica 16, 183-190.

Horat, P. and Semlitsch, R.D. (1994) Effects of predation risk and hunger on the behaviour of two species of tadpoles. Behav. Ecol. Sociobiol. 34, 393-401.

Huey, R. and Pianka, E.C. (1981) Ecological consequences of foraging mode. Ecology 62, 991-999.

Ives, A.R. and Dobson, A.P. (1987) Antipredator behaviour and the population dynamics of simple predatorprey systems. Am. Nat. 130, 431-447.

Lawler, S.P. (1989) Behavioural responses to predators and predation risk in four species of larval anuran. Anim. Behav. 38, 1039-1047.

Lima, S.L. and Dill, L.M. (1990) Behavioural decisions made under the risk of predation: A review and prospectus. Can. J. Zool. 68, 619-640.

May, R.M. (1981) Models for single populations. In Theoretical Ecology: Principles and Applications, 2nd edn (R.M. May, ed.), pp. 7-29. Sinauer Associates, Sunderland, MA.

McCollom, S.A. and Van Buskirk, J. (1996) Costs and benefits of a predator-induced polyphenism in the gray treefrog Hyla chrysoscelis. Evolution 50, 583-593.

McCullagh, P. and Nelder, J.A. (1989) Generalized Linear Models, 2nd edn. Chapman \& Hall, London.

McNamara, J.M. and Houston, A.I. (1987) Starvation and predation as factors limiting population size. Ecology 68, 1515-1519.

McNamara, J.M. and Houston, A.I. (1994) The effect of a change in foraging options on intake rate and predation rate. Am. Nat. 144, 978-1000.

Milinski, M. (1986) Constraints placed by predators on feeding behaviour. In The Behaviour of Teleost Fishes (T.J. Pitcher, ed.), pp. 236-250. Croom-Helm, London.

Morin, P.J. (1983) Predation, competition, and the composition of larval anuran guilds. Ecol. Monogr. 53, 119-138.

Murdoch, W.W. and Oaten, A. (1975) Predation and population stability. Adv. Ecol. Res. 9, 1-131.

Numerical Algorithms Group (1987) The GLIM System Release 3.77 (C.D. Payne, ed.). Numerical Algorithms Group, Oxford.

Peacor, S.D. and Werner E.E. (1997) Trait-mediated indirect interactions in a simple aquatic community. Ecology 78, 1146-1156.

Ruxton, G.D. (1995) Short term refuge use and stability of predator-prey models. Theor. Pop. Biol. 47, 1-17.

Schaffner, A.K. (1996) Influence of predator presence and prey density on behaviour and growth of damselfly larvae (Ischnura elegans). Dipl. thesis, University of Zürich, Zürich.

Sih, A. (1987a) Predators and prey lifestyles: An evolutionary and ecological overview. In Predation: Direct and Indirect Impacts on Aquatic Communities (W.C. Kerfoot and A. Sih, eds), pp. 203-224. University of New England Press, Hanover, NH.

Sih, A. (1987b) Prey refuges and predator-prey stability. Theor. Pop. Biol. 31, 1-12.

Skelly, D.K. (1992) Larval distributions of spring peepers and chorus frogs: Regulating factors and the role of larval behaviour. PhD dissertation, University of Michigan, Ann Arbor, MI.

Skelly, D.K. (1994) Activity level and the susceptibility of anuran larvae to predation. Anim. Behav. 48, 465468.

Skelly, D.K. and Werner, E.E. (1990) Behavioural and life-historical responses of larval american toads to an odonate predator. Ecology 71, 2313-2322.

Smith, D.C. (1983) Factors controlling tadpole populations of the chorus frog, Pseudacris triseriata, on the Isle Royale. Ecology 64, 501-510.

Smith, D.C. (1987) Adult recruitment in chorus frogs: Effects of size and date at metamorphosis. Ecology 68, 344-350.

Van Buskirk, J. (1989) Density-dependent cannibalism in larval dragonflies. Ecology 70, 1442-1449.

Weisser, W.W., Wilson, H.B. and Hassell, M.P. (1997) Interference among parasitoids: A clarifying note. Oikos 70, 173-178.

Werner, E.E. (1991) Nonlethal effects of a predator on competitive interactions between two anuran larvae. Ecology 72, 1709-1720. 
Werner, E.E. (1992a) Competitive interactions between woodfrog and northern leopard frog larvae: The influence of size and activity. Copeia 1992, 26-35.

Werner, E.E. (1992b) Individual behaviour and higher-order interactions. Am. Nat. 140, S5-S32.

Werner, E.E. and Anholt, B.R. (1993) Ecological consequences of the tradeoff between growth and mortality rates mediated by foraging activity. Am. Nat. 142, 242-272.

Werner, E.E. and Anholt, B.R. (1996) Predator induced behavioural indirect effects: Consequences to competitive interactions in anuran larvae. Ecology 77, 157-169.

Wilbur, H.M. (1987) Regulation of structure in complex systems: Experimental temporary pond communities. Ecology 68, 1437-1452.

Wissinger, S.A. (1989) Seasonal variation in the intensity of competition and predation among dragonfly larvae. Ecology 70, 1017-1027.

Wissinger, S.A. and McGrady, J. (1993) Intraguild predation and competition between larval dragonflies: Direct and indirect effects on shared prey. Ecology 74, 207-218.

Woodward, B.D. (1983) Predator-prey interactions and breeding-pond use of temporary-pond species in a desert anuran community. Ecology 64, 1549-1555.

Wooton, J.T. (1993) Indirect effects and habitat use in an intertidal community: Interaction chains and interaction modification. Am. Nat. 141, 71-89.

Wooton, J.T. (1994) The nature and consequences of indirect effects in ecological communities. Ann. Rev. Ecol. Syst. 25, 443-446. 